\title{
Knowledge and Attitudes of Nurses Regarding Pain in the Intensive Care Unit Pa- tients in Rwanda
}

\author{
Christine M. Ufashingabire ${ }^{1 *}$, Etienne Nsereko², Kato J. Njunwa ${ }^{3}$, Petra Brysiewicz ${ }^{4}$ \\ 1,2University of Rwanda, College of Medicine and Health Sciences, School of Health Science \\ ${ }^{3}$ University of Rwanda, College of Medicine and Health Sciences, Directorate of Research, Innovation and Postgraduate studies \\ ${ }^{4}$ University of KwaZulu-Natal, School of Nursing and Public Health, South Africa
}

\begin{abstract}
Background: Pain is a significant burden experienced by patients admitted to the adult Intensive Care Unit (ICU). Acute

conditions associated with severe pain include surgical incision, traumatic wounds, effect of prolonged immobility, and sometimes hidden infections in the body's cavities and treatment by invasive procedures. Pain in ICU is difficult to assess due to the nature of patients admitted to that unit. Pain assessement requires health care providers to have a good knowledge of it, and involves a number of care providers including the nurses among others. However little is known about the nurses knowledge and attitudes related to pain management in ICU. The purpose of this study is to assess nurses knowledge and attitudes toward pain management of ICU patients in three university teaching hospitals in Rwanda. Methods: The tool and attitudes Survey Regarding Pain "developed by Ferrell and McCaffery was adapted to local context. The tool was used in the three referral hospitals in Rwanda to assess knowledge and attitudes from 69 nurses practicing in ICU. We compared the pain management performance in regard to the age, level of education, experience and history of training in pain management between nurses. The researcher used one way ANOVA to compare nurses' scores among hospitals with a significance level $a=0.05$. A multiple linear regression analysis was used to highlight independent factors associated with best performance. A $p$ value $\leq 0,05$ was considered as statistically significant. Results: The results from this study showed that nurses lack adequate knowledge and have poor attitudes toward pain management. The level of nursing education $(p<0.008)$ and the hospital where nurses worked $(P<0.0001)$ had a strong influence on attitudes toward pain management. In addition, knowledge gap and inappropriate attitude towards pain management noticed among some ICU nurses could lead to their underestimation of pain, and under medication. Conclusion: Poor performance in pain management in ICU is multifactorial. Continuous Professional Training and improved working environment towards standard practice are key to pick up that performance.
\end{abstract}

Key words: Intensive care unit, pain management, nurses, knowledge attitude, medication

\section{Introduction}

In critical care settings, moderate to severe pain has been identified as a common cause of patient stress (Kabes, Graves, \& Norris, 2009). Accurate assessment of pain is paramount for appropriate pain management. Evidence indicates that substantial pain coupled with an ICU environment alters patients' normal sensory stimuli and increases their perception of pain (Gélinas, et al., 2004). Many patients admitted to ICUs are already compromised with chronic and acute conditions associated with severe pain, and treating these conditions may escalate pain by requiring painful procedures including but not limited to catheterization, intubation, and chest tubes.

Uncontrolled pain produces complications owing to stimulation of the sympathetic nervous system, hyperglycemia, lipolysis, muscles breakdown, and delayed wound healing. In addition, anxiety, confusion, sleep disturbance, delirium, and paranoia also result from unmanaged pain (Gélinas et al., 2004). Nurses' ability to identify and adequately manage pain is multifactorial and includes 1) ability to interpret verbal and non-verbal signs of pain, 2) cultural bias 3) knowledge gap and 4) excessive concern about administering pain killers (Sloman,et al 2001). Narayan (2010) conducted a study and found that registered nurses under-assessed severe pain. The author also revealed that participants had inadequate knowledge about pain, use of analgesics, addiction, and the risks of respiratory depression.

In a study conducted by Taylor, Gostin, and Pagonis (2008), it was found that inadequacy in the treatment of pain is a worldwide problem, which raises a big concern. However there is evidence that positive change is taking place in many countries. In Romania, for instance, the administrative process to obtain medical opioids and to prescribe strong opioids for patients with severe pain is becoming easier and easier thanks to the new narcotics legislation and regulations, regardless of the underlying cause of the pain that is being treated (Taylor et al., 2008). Poor understanding and lack of education regarding pain and pain medication are attitudinal barriers to its adequate treatment.

In both high and low income countries there is concern that opioids used in routine pain management may lead to addiction. However, it can also be a result of inadequate training in pain management, especially in resource poor areas where lack of training in pain management is marked. Supplies of opioids are limited, and often restricted to specific health facilities (Taylor et al., 2008). In a study conducted by Rampanjato et al.(2007) in Central Africa, $8 \%$ of the nurses involved admitted to being unable to effectively assess pain, while $67 \%$ admitted to fearing administering morphine to patients in emergency cases.

According to Narayan (2010), to a great extent, an individual's way of thinking and acting depends on the cultural group s/he belongs to. This author highlights the importance of cultural aspect of pain management. Therefore, when caring for their patients in general, and those experiencing pain in particular, nurses should consider their cultural values, beliefs and behaviors. Despite the evidence that people feel or react to pain almost in the same way, the fact that members of some racial groups are 
more lenient to pain and able to bear it for a longer time than others is also well documented. For instance, Korol and Craig (2001) and Taylor et al.(2008), maintain that cultural patterns significantly control or manipulate individuals in all their dimensions of life. This means that people's reaction to pain will differ depending on communities. In Rwanda, no cultural bias regarding stoicism has been documented so far. People may attempt to keep their faces covered and try to hide the pain they are feeling by grimacing. Stoicism may lead to nurses working in ICUs running the risk of not recognizing the suffering patient. They may be tempted to believe that those patients who do not show overt signs of pain are not experiencing pain that requires treatment. With regard to pain management, nurses working in ICUs are nowadays faced with many challenges, For instance when caring for critically ill patients, nurses may find it challenging to simultaneously provide effective pain relief and cope with life threatening situations (Subramanian, et al., 2011). In addition, given that there is a shortage of skilled staff in pain medication, it is unwieldy for them to give an efficient dose that meets a patient's analgesic demands (Glynn \& Ahern, 2000).

Most literature documented about pain management in Australia, the United States and Europe. Little is known from sub-Saharan Africa and no literature to date addresses the knowledge and attitudes of Rwandan ICU nurses in regard to pain assessment and management. This study is designed to fill that gap. Findings from this study can be used to help to shape nursing education, nursing practice, and nursing policy in Rwanda.

\section{The objectives of this study were:}

1. To assess the level of Rwandan nurses' knowledge and attitudes regarding pain management of ICU patients.

2. To identify barriers to the optimal management of pain among ICU nurses

\section{Methods}

A quantitative descriptive survey was conducted with the aim of assessing ICU nurses' knowledge and attitudes toward pain management in three referral hospitals in Rwanda, two public and one private hospital. These hospitals were selected because they have ICU's and treat critical cases that need specialized care. These ICUs receive critically ill patients from within and from other hospitals and admit patients aged more than one month. Patients having a wide variety of chronic and acute illnesses, are treated there. The total number of the beds in three ICUs is 22. They were 69 nurse participants in this study classified into two main groups: enrolled and registered nurses. Enrolled nurses are nurses who underwent 6 years of secondary school education with nursing components and have certificate. While registered nurses are nurses who completed from a three-year university comprehensive nursing program and above (Advanced diploma, Bachelor and masters degree in nursing). They were $85.5 \%$ registered nurses and $14.5 \%$ enrolled nurses. The study sample included all registered and enrolled nurses working in ICUs in the three hospitals studied.

A standardized questionnaire used, was developed by Ferrell and McCaffery (2008) known as the "Knowledge and Attitudes Survey Regarding Pain". Permission to use this tool was obtained from its developers. Concerning the established validity and reliability, the content of the tool used was derived from current standards of pain management such as the American Pain Society, the World Health Organization, and the Agency for Health Care Policy and Research. The content validity of this questionnaire was established by a review of pain experts (Breu et al., 2008), whereas construct validity was established by comparing scores of nurses at various levels of expertise such as students, new graduates, oncology nurses, graduate students, and senior pain experts. The tool was identified as discriminating between levels of expertise. Test-retest reliability was established $(a>0.80)$ by repeat testing in a continuing education class of staff nurses $(n=60)$ (Breu et al., 2008). The questionnaire was originally developed in English in the United States. Rwandan participants were both English and French speaking, and participants were given a choice as to which version to complete. A translation and back translation was performed by a professional translator from the University of Rwanda Language Center. Of the 38 total items, four (10.5\%) were adapted to fit the context of Rwandan ICU nurses. Three items were revised because the medications mentioned are not available in Rwanda. Concerning item 18, the original question mentioned a drug called Vicodine that is not available locally. Therefore, the item was removed from the questionnaire. One item was revised to reflect the socioeconomic homogeneity of the country .To ensure validity of the revised tool, a pilot study involving 4 nurses was conducted. Considering that the tool did not have a good performance cut-off point for good level of knowledge, $80 \%$ and above was adopted as good level based on other similar studies (Smart, 2005).

Anonymity of participants was respected and permission from the internal review board of each of three hospitals was obtained. Participants were given assurance that the information they would give would be confidential and used for the sole purpose of the current study, after which they gave their informed consent to participate. Prior to data collection, participants were provided with explanations regarding the aim of the study and how the researcher was going to proceed. The data collection process started after obtaining the ethical clearance and permission from the referral hospitals to conduct the study. The researcher made appointment on the phone and asked to the participants if they were ready to participate, after which they were informed of the schedule for data collection. Participants were requested to fill in the questionnaire during their free time in the hospital setting. Participants completed questionnaires individually. All questionnaires were completed anonymously and placed in a secure box in the hospital lounge.

The tool is divided into three sections. The first section comprised of socio-demographic information including participant age, gender, area of clinical practice, level of education, and pain management training status. Section two consisted of 22 true / false items and 14 multiplechoice items. There were also 2 case studies where participants were asked to make a decision regarding pain and medication. The third section dealt with specific questions related to barriers to optimal pain management in ICUs. It had 5 items with a 4 rating scale ranging from "No importance" to "Major importance".

Data coding, processing, and analysis was performed using SPSS version 18. Descriptive statistics, including frequency tables, mean and standard deviation, maximum and minimum observations calculation were used to summarize demographic data of participants. For items in the second section of the data collection tool, data were summarized using a frequency table. This section combined both knowledge and attitudes as recommended by tool 
developers. In order to check whether working in one of the three referral hospitals influences the nurses' judgments on barriers to pain management, a set of items from the knowledge and attitude data collection tool was selected and rephrased to stand for potential barriers to optimal pain management in ICUs. The researcher used oneway ANOVA to compare the nurses' mean scores across hospitals.. It was this mean score that was used to make a comparison between hospital groups. The significance level (a) was set to 0.05. A multiple linear regression was used to test whether socio- demographic characteristics (ICU experience, hospital site, on-job training and nurses' level of education) influenced the participants' judgments on potential barriers to optimal pain management (dependent variable).

\section{Results}

In this study, information regarding the socio-demographic characteristics shown that the majority of participant were female $(64.6 \%, n=45)$, with mean age of $(34.1+/-5.2)$ had advanced diploma in nursing $(69.5 \%, n=48)$ with mean working experience of $2.9+/-2.8$ years. Participants who had attended on-the-job training represented $40.5 \%(n=28)$.

Table 1. Participants' Socio-demographic characteristics.

\begin{tabular}{lll}
\hline Gender & Frequency & Percent \\
\hline Male & 24 & 34.3 \\
Female & 45 & 64.6
\end{tabular}

\section{Level of education:}

1. Certificate (enrolled nurses) 10

14.5

2. Advanced diploma

3. Bachelor degree

4. Masters degree

1

On-the-job training on pain management:

$\begin{array}{lll}\text { 1. Yes } & 28 & 40.5 \\ \text { 2. No } & 41 & 59.4\end{array}$

Age (in years): mean=34.1; $\mathrm{SD}=5.2 ; \mathrm{Min}=25 ; \mathrm{Max}=45$

ICU years of experience: Mean=2.9, SD=2.8; $M i n=1 ; M a x=16$

Concerning the knowledge and attitudes of nurses, Table 2 shows the "True" or "False" questions with which the participants were presented. The results indicate the percentage of the participants who correctly answered individual items of the data collection tool. From this table, it can be seen that $85.5 \%$ of the participants believe that patients should not be encouraged to endure as much pain as possible before using opioids (item 13). This item recorded the highest number of correct answers. In the same table, item 3 asked whether patients who can be distracted from pain do not have severe pain. This is the item that recorded the lowest number of correct answers, with only $58 \%$ of the participants providing correct answers to it. As for items $6,7,8,9$, and 10, about $70 \%$ of the participants answered them correctly.
Table 2. Number of participants who answered correctly to each 'true"/"false" item on the Nurse' Knowledge and Attitude Survey Regarding Pain ( $\mathrm{N}=69)$ Item by item analysis

Item content area

Correct

answer

Frequency

(\%)

1. Vital signs are always reliable indicators of

43

62.3

the intensity of a patient's pain $(F)$

2. Because their nervous system is underdeveloped, children under two years of age have decreased pain sensitivity and limited memory of painful experiences ( $F$ )

3. Patients who can be distracted from pain usually do not have severe pain (F)

4. Patients may sleep in spite of severe pain ( $T$ )

5. Aspirin and other non-steroidal antiinflammatory agents are NOT effective analgesics for painful bone metastases (F)

6. Respiratory depression rarely occurs in patients who have been receiving stable doses of opioids over a period of months ( $T$ )

7. Combining analgesics that work by different mechanisms (e.g. combining opioid with an NSAID) may result in better pain control with fewer side effects than using a single analgesic agent $(\mathrm{T})$

8. The usual duration of analgesia of 1-2 mg morphine IV is 4-5 hours (F)

9. Research shows that promethazine 48 (Phenergan) and hydroxyzine (Vistaril) are Reliable potentiators of opioid analgesics (F)

10. Opioids should not be used in patients with a history of substance abuse $(F)$

11. Morphine has a dose ceiling (i.e., a dose above which no greater pain relief can be obtained) (F)

12. Elderly patients cannot tolerate opioids for pain relief $(F)$

13. Patients should be encouraged to endure as much pain as possible before using an opioid (F)

14. Children less than 11 years old cannot reliably report pain so nurses should rely solely on the parent's assessment of the child's pain intensity $(F)$

15. Patients' spiritual beliefs may lead them to think pain and suffering are Necessary ( $T$ )

16. After an initial dose of opioid analgesic is given, subsequent doses should be adjusted in accordance with the individual patient's response $(T)$

17. Giving patients sterile water by injection (placebo) is a useful test to determine if the pain is real $(F)$

18. If the source of the patient's pain is unknown, opioids should not be used during the pain evaluation period, as this could mask the ability to correctly diagnose the cause of pain $(F)$ 
Table 2. Number of participants who answered correctly to each 'true"/"false" item on the Nurse' Knowledge and Attitude Survey Regarding Pain ( $\mathrm{N}=69)$ Item by item analysis cont'd

\begin{tabular}{lll}
\hline Item content area & $\begin{array}{l}\text { Correct } \\
\text { answer } \\
\text { Frequency } \\
\text { (\%) }\end{array}$ & \\
\hline $\begin{array}{l}\text { 19. Anticonvulsant drugs such as Phenytoin } \\
\text { produce optimal pain relief after a single }\end{array}$ & 52 & 75.4 \\
dose (F) & & \\
20. Benzodiazepines are not effective pain & 50 & 72.5 \\
relievers unless the pain is due to muscle & & \\
spasm (T) & 43 & 62.3 \\
21. Narcotic/opioid addiction is defined & & \\
as a chronic neurobiological disease, \\
characterized by behaviors that include one \\
or more of the following: impair control over \\
drug use, compulsive use, continued use \\
despite harm, and craving (T).
\end{tabular}

To assess the extent to which participants pay attention to potential barriers to pain management, participants were asked to rate five potential barriers to optimal pain management in their respective ICUs on a 4-point Likert scale from "no importance" to "major importance". The researcher found that only $18 \%$ of the participants rated the said barriers as having "major importance".

Table 3. Rating of the importance of barriers to optimal pain management in the respondent's setting

\begin{tabular}{|c|c|c|c|c|c|c|c|c|}
\hline \multirow[t]{2}{*}{ Item } & \multicolumn{2}{|c|}{$\begin{array}{l}\text { No } \\
\text { importance }\end{array}$} & \multicolumn{2}{|c|}{$\begin{array}{l}\text { Little } \\
\text { importance }\end{array}$} & \multicolumn{2}{|c|}{$\begin{array}{l}\text { Moderate } \\
\text { importance }\end{array}$} & \multicolumn{2}{|c|}{$\begin{array}{l}\text { Major } \\
\text { Importance }\end{array}$} \\
\hline & $n$ & $\%$ & $n$ & $\%$ & $n$ & $\%$ & $n$ & $\%$ \\
\hline $\begin{array}{l}\text { 1.Inadequate } \\
\text { assessment of } \\
\text { pain relief }\end{array}$ & 9 & 13 & 33 & 48 & 9 & 13 & 18 & 26 \\
\hline $\begin{array}{l}\text { 2. Patient's } \\
\text { capacity to } \\
\text { report pain }\end{array}$ & 9 & 13 & 27 & 39 & 28 & 40.5 & 5 & 7.2 \\
\hline $\begin{array}{l}\text { 3.Inadequate } \\
\text { staff } \\
\text { knowledge } \\
\text { of pain } \\
\text { management }\end{array}$ & 9 & 13 & 22 & 32 & 13 & 19 & 25 & 36 \\
\hline $\begin{array}{l}\text { 4. Nursing staff } \\
\text { reluctance to } \\
\text { administer } \\
\text { opioids }\end{array}$ & 4 & 6 & 27 & 39 & 34 & 49 & 4 & 6 \\
\hline $\begin{array}{l}\text { 5.Lack of } \\
\text { equipment or } \\
\text { skills in using } \\
\text { equipment }\end{array}$ & 9 & 13 & 24 & 35 & 24 & 35 & 12 & 17 \\
\hline $\begin{array}{l}\text { Total } \\
\text { percentages }\end{array}$ & $12 \%$ & & $35 \%$ & & $31 \%$ & & & $18 \%$ \\
\hline
\end{tabular}

The knowledge and attitudes toward pain was assessed for the three hospitals. The results indicated that at least one group of participants differs from the other two groups in paying attention to potential barriers that can hinder the optimal pain management in ICU (F test $=74.1, p<0.001)$ depending on their working hospitals.
To identify which group is different from the others, we conducted a PosHoc pair-wise difference. The results of the table 4 show that there are differences between groups, with Hospital A being significantly different from the other two hospitals ( $p<0.001$ and $\mathrm{Cl}=0.8697-1.2520$ ).

Table 4. Comparison of nurses' performance according to the hospitals they work

\begin{tabular}{llll}
\hline $\begin{array}{l}\text { Hospitals } \\
\text { compared }\end{array}$ & $\begin{array}{l}\text { Difference in } \\
\text { performance }\end{array}$ & $95 \% \mathrm{Cl}$ & PValue \\
\hline A versus B & 1.06087 & {$[0.8697-1.2520]$} & $<0.001^{*}$ \\
A versus C & 1.01087 & {$[0.8067-1.2151]$} & $<0.001$ \\
B versus C & -0.05 & {$[0.2486-0]$.} & 0.617 \\
\hline
\end{tabular}

${ }^{*}$.The mean difference is significant at $a=0.05$ level

Table 5 presents the results of linear regression of the total score on questions related to potential barriers to pain management when a set of participants' independent socio-demographic variables is taken into account. The results show that the overall model was significant at $p<$ 0.001, the overall R2 was 52\%, which means that 52\% of the variation of the total score was accounted for by the socio-demographic variables that were used in the model. With regard to individual coefficients, Table 5 shows that working in one of the three hospitals predict significantly the score on the barriers to optimal pain management ( $\beta=$ -0.663, $p<0.001$ ). The same goes for participants' level of education. The results above rightly suggest that having a high level of education in nursing significantly predicts one's perceptions of potential barriers to pain management ( $\beta=$ 0.247, $p=0.008$ ).

Table 5. Model predicting Total correct score using barriers

\begin{tabular}{lllll}
\hline \multicolumn{5}{c}{ Dependent variables: total correct score } \\
\hline Variables & Coefficient & SE & T & P \\
\hline ICU experience & -0.083 & 0.054 & -0.932 & 0.355 \\
$\begin{array}{l}\text { Working in one of } \\
\text { the hospitals }\end{array}$ & -0.663 & 0.070 & -7.058 & $<0.001^{* *}$ \\
$\begin{array}{l}\text { On-the-job- } \\
\text { training on pain } \\
\text { management }\end{array}$ & 0.075 & 0.114 & 0.788 & 0.434 \\
Level of education & 0.247 & 0.083 & 2.755 & $0.008^{*}$ \\
\hline
\end{tabular}

*Significant at $a=0.01{ }^{* *}$ Significant at $a=0.001$

\section{Discussion}

The purpose of this study was to assess the knowledge and attitudes of the Rwandan nurses regarding pain management of ICU patients and find out what might be the barriers to providing optimal pain management. The socio-demographics results show that the majority of the participants were young adults and mostly females, confirming findings from other studies that nursing is a female-dominated career (Ozdemir, Akansel, \& Tunk, 2008). The majority of the nurses had Advanced diploma training reflecting an increasing number of them relative to the Certificate level enrolled nurses owing to capacity building efforts of the nursing staff.

Given that the content of the items 6, 7, 8, 9 and 10 in the tool focuses mostly on opioids' side effects, it can be suggested that participants have concerns related to these side effects. When it comes to item number 3 , the results show that it recorded the most failed by participants. It 
can be suggested that, probably, participants have been culturally influenced. In fact, in Rwandan culture, many people believe that remaining calm and focused when one is experiencing pain helps to alleviate it.

Concerning the Knowledge of nurses on the importance of barriers to pain management shown in the table 3 , results are different from those published by Smart (2005) where only two of the barriers among eight were rated by $50 \%$ or more of the sample as being of major importance in their setting. Also in the study conducted by Fairbrother et al, (2003) responses to questions regarding the 5 barriers that are referred to are considered to be correct only if they are rated as having "major importance". Given that the big majority of the participants in the present study gave answers other than "Major importance", the only logical conclusion to be drawn from the findings is that a great number of nurses pay little importance to barriers to pain management or simply do not know them.

From the findings of the Table 4 , it can be seen that there are differences between groups, with Hospital A being significantly different from the other two hospitals

The results from this study are comparable to the findings published by other studies. Hsiang et al.( 2010), reported a significant difference in perceiving barriers to pain management in specific ICU, and this difference was observed according to hospital accreditation. From the results above, it can be concluded that the difference observed between groups suggests that participants working in Hospital A are more barriers cautious than those from the other two hospitals. The difference observed is probably related to the accreditation level of the hospitals since Hospital A is of high quality standards and organize regular refresher courses for its personnel.

The results of Table 5 shows that working in one of the three hospitals predict significantly the score on the barriers to optimal pain management. The same goes for participants' level of education. However, ICU experience and on-jobtraining did not significantly predict the participants' score related to barriers on pain management. The results above rightly suggest that having a high level of education in nursing significantly predicts one's perceptions of potential barriers to pain management. These findings are similar to the study conducted by Smart (2005) which showed that nurses educated at different level in Britain and Canada had significantly higher scores than those educated in the Philippines. Furthermore, clinical educators and clinical nurse specialists' scores were significantly higher than those of registered nurses and registered nursing assistants. Also, the scores of nurses with a masters or a baccalaureate level were significantly higher than those of nurses with a diploma or a registered nursing assistant certificate. It was also found that the scores of nurses with a university level of education were higher than those of nurses who have not attended university. In another study, (Linda, 2008) confirmed previous results and demonstrated the impact of education on pain management. This author concluded that knowledge is established and carried on through additional academic education and the clinical setting in which nurses practice their nursing skills. The findings of Linda lend support to the results of another study conducted by Erkes \& Veronica G. Parker( 2001), demonstrated that a continuous education program on pain management helps to increase awareness of, and skills, in that area. The views above are shared by Lui, So, \& Fong(2008).These researchers maintain that knowledge is not only acquired by means of formal education but also through daily practice as a way of learning. Their observation accounts for the finding of the present study that experience, as well as level of education, independently contributes to the variation between the scores of the participant.

\section{Conclusion}

The present study has described ICU nurses' knowledge and attitudes towards pain management. It was conducted in three referral hospitals in Rwanda. The overall results show that these nurses lack adequate knowledge and have poor attitudes as far as the items related to pharmacology, clinical assessment and understanding of the importance of barriers to pain management are concerned. A comparison was made between the nurses based on the hospitals where they work. It was found that scores on barriers to pain assessment and management vary depending on the participants' hospital site. One hospital was outstanding .Also level of education was a determining factor for all the participants in the three hospitals, that is, it influenced the performance of the participants.

It can be concluded that participants have knowledge gap about, and poor attitudes towards, pain assessment and management. For this reason, protocols should be designed and implemented to increase nurses' knowledge about, and improve their attitudes towards, pain management, for better satisfaction and well-being of the patients.The organization of Continuous professional development ,refresher courses and encourage the upgrading the level of education of nurses are also important.

\section{Limitation to the study}

This study used a self-report questionnaire to collect data. In addition, the original tool that was used was in English and has been translated into French. It is this translated version of the tool that was used to collect data. It is known that the most demanding aspect of cross-cultural translation is to adjust the instrument in a complete and appropriate cultural form while keeping the meaning of the original items. As well as linguistic problems that may arise, there is also the challenge to maintain accuracy and to match the cultural differences of the two languages. It is therefore possible that some items in the translated version may have some semantic differences from the original tool, which may have influenced the instrument's validity. With regard to generalization, the current study recruited a relatively small sample (69 participants) from three referral hospitals. Extrapolation of such results to other nurses in district hospitals in Rwanda is limited.

\section{Recommendation}

This study has identified areas of knowledge gap and poor attitudes as far as ICU nurses are concerned. The results of this study can be used to improve the management of patients experiencing pain. Unity managers and matrons should organize Continuous Professional Training on pain management for nurses. Furthermore, the stakeholders should upgrade the educational level of nurses.

\section{Acknowledgment}

We are grateful to the New Partnership for Africa's Development (NEPAD) to sponsor this research study and nurses participated in the study. 


\section{Conflict of interest}

All authors report no conflict of interest.

\section{Authors' contributions}

PB and EN led the study conception, design, analysis and interpretation of results. KJN has mentored the manuscript writing and editing.

\section{References}

Breu, F., Guggenbichler, S., \& Wollmann, J. (2008). Knowledge and Attitudes Survey Regarding Pain. Vasa, (October). http://doi.org/10.1089/ jpm.2007.9828.

Erkes, E. B., \& Veronica G. Parker, R. L. C. and R. M. M. (2001). An Examination of Critical Care Nurses' Knowledge and Attitudes Regarding Pain Management in Hospitalized Patients. Pain Management Nursing, 2(2), 47-53.

Fairbrother, G., Jastrzab, G., Kerr, S., \& Mclnerney, M. (2003). Profiling the "pain aware" nurse: acute care nurses' attitudes and knowledge concerning adult pain management. Australian Journal of Advanced Nursing, The, 21(2), 27. Retrieved from http://search.informit.com.au/ dentSummary; $d n=404975665129874 ;$ res=IELHEA

Gélinas, C., Fortier, M., Viens, C., Fillion, L., \& Puntillo, K. (2004). Pain assessment and management in critically ill intubated patients: A retrospective study. American Journal of Critical Care, 13(2), 126 135.

Glynn, G., \& Ahern, M. (2000). Determinants of critical care nurses. pain management behavior. Australian Critical Care, 13(4), 144-151.

Hsiang-Ling Wang and Yun-Fang Tsai. (2010). Nurses' knowledge and barriers regarding pain management in intensive care units. Journal of Clinical Nursing, $19,3188-3196$

Kabes, A. M., Graves, J. K., \& Norris, J. (2009). Further validation of the nonverbal pain scale in Intensive care patients. Critical Care Nurse, 29(1), 59-66.

Korol, C. T., \& Craig, K. D. (2001). Pain from perspectives of health psychology Colombia: Vancouver. Linda, F. (2008). Pain control in palliative care : a South African nursing perspective. CPUT Theses \& Dissertations. Paper 30. Retrieved from http://dk.cput. ac.za/td_cput/30

Lui, L. Y. Y., So, W. K. W., \& Fong, D. Y. T. (2008). Knowledge and attitudes regarding pain management among nurses in Hong Kong medical units. Journal of Clinical Nursing, 17(15), 2014-21. Retrieved from http://www.ncbi.nlm.nih.gov/pubmed/18720572

Narayan, M. C. (2010). Culture's effects on pain assessment and management. The American Journal of Nursing, 110(4), 38-47; quiz 48-49. http://doi. org/10.1097/01.NAJ.0000370157.33223.6d

Ozdemir, A., Akansel, N., \& Tunk, G. (2008). Gender and career: Female and male nursing students. perceptions of male nursing role in Turkey. Health Science Journal, 2(3), 133-161.
Rampanjato, R. M., Florence, M., Patrick, N. C., \& Finucane, B. T. (2007). Factors influencing pain management by nurses in emergency departments in Central Africa. Emergency Medicine Journal, 24, 475-476.

Sloman, R., Ahern, M., Wright, A., \& Brown, L. (2001).

Nurses' Knowledge of Pain in the Elderly Rod Sloman. Journal of Pain and Symptom Management (Vol. 21). Sydney, New South Wales, Australia: The University of Sydney, Sydney, New South Wales, Australia.

Smart, S. (2005). Post-operative pain management knowledge and attitudes of paediatric nurses: A New Zealand regional view. , Victoria University of Wellington, Wellington, New Zealand. Thesis.

Subramanian, P., Allcock, N., James, V., \& Lathlean, J. (2011). Challenges faced by nurses in managing pain in critical care setting. Journal of Clinical Nursing, 1-9.

Taylor, L. A., Gostin, O. L., \& Pagonis, A. K. (2008). Ensuring effective pain treatment. A national and global perspective. Journal of American Medical Association, 299(1), 89-91. 